\title{
ASPECTOS DA PRODUÇÃO E CONSUMO DE FLORES E PLANTAS ORNAMENTAIS NO BRASIL
}

\author{
AUGUSTO AKI ${ }^{1}$ e JOSÉ MATHEUS YALENTI PEROSA²
}

\section{RESUMO}

O presente artigo tem por objetivo uma análise sobre a constituição do mercado de flores e plantas ornamentais no Brasil, aspectos de marketing envolvidos nessa evolução e a sistematização de informações sobre produção e consumo. Inicialmente, é apresentada a evolução desse mercado, elaborada a partir de estudos de técnicos e consultores da área. Segue-se a apresentação de dados e informações de estudos e pesquisas elaborados sobre a evolução da produção. A maioria das informações apresentada consta da pesquisa de campo "Prospecção de Produtos e Mercados: Cadeia Produtiva Nacional", levada a efeito pelo Instituto Brasileiro de Floricultura (IBRAFLOR) com o apoio da Agência de Promoção de Exportações (APEX), e publicada no início de 2003. Com base na estruturação do mercado, produção e consumo, são sugeridas ações visando à maior eficiência da cadeia.

\section{INTRODUÇÃO}

Desde que o homem é homem, o consumo de flores existiu. Há relatos de descobertas em sítios arqueológicos, onde os locais em que se enterravam os membros do grupo eram adornados com flores. Mais incrível ainda é o fato de alguns procedimentos comerciais adotados hoje terem sido mantidos desde aquela época...

Pulando alguns séculos, podemos encontrar um novo momento de destaque para as ornamentais, nos famosos jardins da França, durante o reinado de todos os Luises. Certamente ali nasceu o aspecto aristocrático e o status associado à presença das flores.

No comércio, como tudo pode ser transformado em vendas, temos também alguns fatos curiosos, como, por exemplo, o surgimento do Dia dos Namorados (especialmente a sua adaptação no caso brasileiro):

\section{Como surgiu o Dia dos Namorados?}

Conta a lenda que, em 276 d.C. foi decretado, em Roma, que os homens casados não iriam mais servir em campos de batalha. Os casamentos foram proibidos e precisavam de autorização estatal.

Um padre chamado Valentino rebelou-se e começou a casar as pessoas sem autorização oficial. Ele foi descoberto, preso, torturado e decapitado. Por sua devoção ao amor, ele acabou se tornando um símbolo. Como sua morte foi em fevereiro, o Dia dos Namorados no mundo inteiro é comemorado nessa data.

No Brasil, como isso iria coincidir com o Carnaval, decidiu-se fixar o Dia dos Namorados no dia 12 de junho, véspera de Santo Antônio, o santo casamenteiro (ficando, pois, na seqüencia natural: namoro e casamento).

Assim, Valentine's Day significa, na tradução direta, dia de São Valentino.

Nos tópicos que se seguem, o presente artigo analisa a constituição do mercado de flores e plantas ornamentais no Brasil, aspectos de marketing envolvidos nessa evolução e informações sobre produção e consumo.

\footnotetext{
${ }^{1}$ Consultor de marketing para flores e plantas. Caixa Postal 278. 13825-970 Holambra (SP). Fax 019 3802-1422 e fone 3802-2514. E-mail: consultoria@augusto.aki.nom.br e augustoaki@dglnet.com.br

${ }^{2}$ Departamento de Gestão e Tecnologia Agroindustrial - Faculdade de Ciências Agronômicas - Câmpus de Botucatu - UNESP - Fazenda Experimental Lageado. Caixa Postal 237. 18603-970 Botucatu (SP). E-mail: dede@fca.unesp.br
} 


\section{OS PÓLOS PRODUTORES, CONSTITUIÇÃO DOS MERCADOS E CONSUMO DE FLORES}

No Brasil, a história do mercado de flores costuma ser contada da década dos 50s para cá. A partir daí, podemos começar a associar fatos da produção com os do consumo.

Naquela época, a produção era de entorno. Tudo acontecia ao lado dos grandes centros. São regiões tradicionais as cidades de Atibaia e Holambra em São Paulo e o pioneiro pólo de flores em Pernambuco (pólos mais famosos de então).

No consumo, essa foi a época do primeiro auge do cinema de Holywood. Champanhe, perfumes e flores faziam parte do símbolo máximo do que significava sedução e glamour.

As rosas já nasceram dentro dessa mística e logo assumiram o papel de flor da sedução. Mas em termos de produção, o que reinava no país eram o crisântemo e a palma. O lema do mercado era: "podemos atender em qualquer tipo de flores, desde que seja crisântemo ou palma".

$\mathrm{Na}$ década dos $70 \mathrm{~s}$, com a televisão, as novelas e o Beto Rockfeller, o ambiente ornamentado com flores passou a ser símbolo de status e ascensão social.

$\mathrm{Na}$ produção, isso coincidiu com a famosa "diáspora holambresa". A Cooperativa começou a atender nacionalmente, mediante sete filiais. Esse movimento foi marcante, pois, ao mesmo tempo que pressionou os pequenos produtores artesanais locais a se profissionalizarem, mostrou a outros que esse era um mercado economicamente rentável.

A década dos $80 \mathrm{~s}$ foi a da crise financeira e do estrangulamento do consumo. Para todos os itens tidos como supérfluos, foi uma época dura. As flores estavam nesse meio. Ao mesmo tempo que pressionou negativamente a produção, segurando seu crescimento, possibilitou grande ganho de margem.

Em regiões como o Nordeste, fazer enormes festas com grandes decorações de flores passou a ser sinal de poder. Vem daí a origem desse segmento (decorações) na região.

Em termos de produção, essa foi a época do fortalecimento da região Sudeste. Rio de Janeiro - com sua produção voltada para o mercado local - e Minas Gerais - com seu famoso projeto de exportação em Barbacena, foram os fatos mais marcantes.

Nessa oportunidade, efetuaram-se as primeiras tentativas de venda em supermercados, mas não evoluíram muito. Em termos de produtos, a rosa e a violeta começaram a desbancar as palmas.

Conta a lenda que, durante o inicio do Plano Cruzado, com o aquecimento da economia, que tinha um enorme potencial de consumo represado, vendeu-se na Holambra um novo produto fascinante: tiririca em vaso. $\mathrm{O}$ engenhoso produtor colocava a muda, bastante água, adubo e pronto. $\mathrm{O}$ dinheiro rolava para a conta.

E chegam os anos 90s, que foram o woodstock para o mercado de flores. Rolou de tudo. Logo no início, surgiu o Sistema Veiling, que veio para modificar o mercado.

$\mathrm{O}$ período pode ser dividido em duas partes. $\mathrm{Na}$ primeira metade da década, consolidou-se a região Sul como novo pólo produtor. Rio Grande do Sul, Santa Catarina e Paraná fizeram uma conta simples: quanto consumiam e quanto importavam de flores de outros estados. O destino talvez tenha sido diferente para cada um deles.

O Paraná ainda tenta organizar-se. Muita coisa acontece por lá, todas em direções diferentes. Ainda não há um norte. Santa Catarina, ao contrário, especializou-se e teve melhor resultado: dominou o setor de paisagismo e foi pioneira em tropicais (pasmem!).

No consumo, era o nascimento da ecologia. O evento realizado em 92 no Rio de Janeiro simbolizou tudo isso - a ECO 92. Começam a despertar o consumo próprio e a primeira tentativa dos garden centers.

Finalmente, acontece ainda um fato de tremenda importância simbólica para o mercado de flores: durante as olimpíadas de Barcelona, em 92, todos os premiados recebem um maço de flores. Elas passam a simbolizar a vitória, abrindo as portas das homenagens empresariais.

O mercado cresce. Aumenta a produção, aumenta o varejo e aumenta o consumo. Explode a violeta. $\mathrm{O}$ lema do mercado era: "nesta terra, em se plantando tudo dá".

São desse período os primeiros Encontros de Mercado. Produtores e floristas começam a enxergar que era preciso planejar o todo. Muita tentativa e pouco resultado, mas talvez tivesse que ser assim.

Em uma dessas conturbadas experiências dos anos 90 s, um produtor tentou abrir o mercado de bancas de jornais e postos de gasolina para flores. A idéia era boa, o produto foi desenvolvido especialmente para esse nicho, mas o momento ainda não estava maduro. É interessante perceber agora que esse é o mercado do futuro. 
Na segunda metade da década dos 90s, chegaram os demais participantes da festa. Consolidaram-se o Nordeste e o Centro-Oeste. As flores tropicais, as orquídeas, as mudas para reflorestamento, as begônias, as forrações e os lírios fortaleceram-se no mercado.

Com o aumento da oferta houve achatamento das margens. A concorrência acirrou-se entre os produtores e aquela estória de que cada enxadada era uma minhoca acabou esfriando. As regiões começaram a especializar-se por produto.

Minas Gerais e Pernambuco ficaram com flores de corte. Alagoas, Bahia, Ceará e Pernambuco dominaram as tropicais. Santa Catarina e Goiás fecharam com o paisagismo. Paraná, Santa Catarina e Rio Grande do Sul pegaram as forrações, ficando São Paulo com a comercialização e a produção de flores em vaso.

No mercado, voltaram as tentativas de vendas em supermercados. O volume era necessário e o supermercado, a solução. Praticamente, todas as experiências foram malsucedidas.

Também nessa fase ocorreu a segunda onda dos garden centers. Novamente, ainda não foi aí que eles se firmaram.

Em 1999, começou a fase internet, que, no varejo, representou uma verdadeira gripe: poucas se salvaram. No Btob (venda de fornecedor para varejo) ela nunca decolou - alias, nem aqui nem lá fora.

O destaque dessa época foram os decoradores, um nicho que se fortaleceu e cresceu. Talvez devido a isso, elevou-se a demanda por folhagens, complementos e flores secundárias (alstroeméria, liatriz, flores cacheadas, antúrios, lisiantus, folhagens tropicais). Esse segmento representa um bom mercado até hoje.

Novamente, o mercado tentou encontrar-se. O volume era grande, mas o canibalismo também. Além de quem já estava aqui, havia uma fila crescente de novos produtores querendo entrar. Onde tudo isso acabaria? Nessa época, o dilema do mercado era: como direcionar os novos produtores? Vigorava a regra: "quanto mais fácil, pior".

E viva a rosa, a rosa, cantada em verso, cantada em prosa... Do ponto de vista de marketing de produto, nenhum evoluiu tanto quanto ela. Talvez tivesse mesmo essa responsabilidade, por representar, sozinha, cerca de $30 \%$ do mercado de flores de corte.
Eis algumas inovações que merecem ser destacadas no produto:

- Início da década dos 90s: embalagens tipo "caixas Parmalat" com 5 dúzias.

- Meio da década dos 90s: embalagens específicas, em papelão ou plástico.

- Meio da década dos 90s entrada das rosas importadas (que causou no mercado de flores o mesmo efeito que o Collor falando das nossas carroças...).

- Avanço nas técnicas de pós-colheita.

- Implantação do padrão de 20 botões (internacional).

- Constante lançamento/morte de variedades.

- Final da década dos 90s: adoção do sistema de camisinha para o botão.

- Adoção do tubete na venda para botão.

- Venda em pétalas.

- Atualmente, venda de maços em caixas para que o próprio consumidor faça seu buquê.

- Plantio em substrato elevado.

A chegada do ano 2000 trouxe nova perspectiva para o mercado de flores. O crescimento do setor de flores tropicais coincidiu com o maior enfoque do Governo na exportação e com o fortalecimento do real sobre o dólar.

A APEX teve um papel importante no incentivo à mudança de foco dos produtores. $\mathrm{O}$ acordo com $\mathrm{O}$ IBRAFLOR, a agenda criada para formatar nossos canais de exportação e os trabalhos de divulgação nos eventos mais importantes do segmento na Europa surtiram efeito.

Internamente, além do espaço aberto pelas tropicais na exportação, cresceram no mercado interno a gérbera e as begônias. A seleção de crédito foi marcante nesse inicio de século novo: os produtores despertaram para o fato de que mais vale o lucro que a venda. Junto com ela, veio a seleção de clientes.

A venda nas Ceasas, contudo, apresentou esgotamento. Com o aumento da oferta, o produtor começou a competir com seus pares de modo mais agressivo, e estar sob o mesmo teto representou um calcanhar-de-aquiles. Aqueles entrepostos que não se voltaram para o consumidor, verificaram um aumento de prazo de pagamento insuportável dentro dos floristas.

Do lado do paisagismo seguiu-se o crescimento. Esse setor está muito ligado à industria imobiliária, e os condomínios de alto padrão multiplicaram-se por todo o País. Infelizmente, para esse mercado, a estruturação comercial e a padronização dos produtos são obstáculos a serem vencidos. 
Com efeito, começou a surgir um novo modelo de negócio no mercado: a poupança verde. Tamanha é a demanda por produtos acabados que produtores de diversos pontos do País começaram a investir em áreas de produção para "colheita futura": palmeiras, árvores de madeira de lei etc. "Isso será a herança para meus filhos..."

Também surgiu do paisagismo um novo nicho de mercado: o do reflorestamento, setor especialmente forte no Rio de Janeiro. Em vista das mudanças da legislação, inúmeras oportunidades foram criadas: nos novos projetos industriais, nos novos trechos de rodovias construídos pelas concessionárias etc. Para cada metro quadrado desapropriado, a legislação pede $3 \mathrm{~m}$ de reflorestamento.

Em termos de consumo, vê-se uma forte pressão sobre o varejo tradicional, que já não consegue mais escoar o volume atual de produção. As mulheres e as empresas são os consumidores mais potenciais para esses novos tempos.

O simbolismo também está em alta. O desequilíbrio social, o estresse, a crise no relacionamento familiar e o distanciamento com a natureza têm feito as pessoas voltarem-se para o simples, o básico e o equilíbrio.

Revistas como "Bons Fluidos", "Vida em Equilíbrio" e outras bombardeiam o consumidor, mensalmente, com significados, conteúdo e produtos que atendem a essa demanda. As flores e plantas estão constantemente nessa pauta. Infelizmente, o varejo ainda não atacou adequadamente essas oportunidades.

Como produtos, temos boas perspectivas para os buquês prontos para pontos de venda alternativos e para a venda de botões de rosas em datas secundárias como: Dia das Mulheres, Dia das Secretárias, Dia do Médico, Dia dos Professores...

Os produtores, provavelmente, olharão com muito mais atenção sua abordagem ao consumidor. Eles precisam de uma opção "1.0", ou seja, uma opção de volume. Por meio das Ceasas, vê-se que a desorganização e o custo acabam por dificultar os volumes.

Provavelmente, esse caminho será feito mediante os garden centers ou as Redes Bandeiradas de Varejo. O primeiro caso é auto-explicativo (apesar de ainda não estar completamente formatado para o mercado brasileiro). No segundo, temos o modelo mais inovador.

O fornecedor (produtor ou atacadista), após um processo de seleção de clientes, faria investimentos diretamente no ponto de venda, em termos de ex- positores, material de decoração e de divulgação. Por esse trabalho, ele obterá compromissos de volume da loja. Juntos, enfrentarão os desafios do consumo e terão vantagens sobre os demais agentes que continuarão com suas tradicionais relações de cliente/ fornecedor. Para quem quiser aprofundar-se nesse modelo, é preciso estudar o sistema "Keiretsu" japonês ou, aqui mais perto, o modelo de vendas feito pelo grupo atacadista Martins, de Uberlândia.

Os supermercados passaram a comprar diretamente do Veiling em 2002, o que também deve dar um novo fôlego a esse segmento. Mais pressão para o varejo tradicional e para o fornecedor que atende a esse setor. Mais um motivo para reorganizar-se comercialmente: se nada for feito, todo vento será negativo para o produtor.

Para o futuro, o produtor deve olhar com bastante carinho para o Centro-Oeste, em franco progresso pelo setor agrícola, pecuário e exportação. $\mathrm{O}$ dinheiro flui e, com isso, todo mercado gira. Há um sistema de abastecimento deficiente em termos de flores de corte e muitas oportunidades para a produção de tropicais e flores para decoração.

Para o varejo, o setor de paisagismo e o de decoração são muito interessantes.

A história se escreve no dia-a-dia. Daqui a dez anos, quando estivermos em um mercado amadurecido, poderemos olhar para esse período e identificar claramente os fatos importantes que marcaram o mercado e influenciaram seu futuro.

Uma curiosidade muito interessante é a analise da evolução do comportamento de consumo nas datas de pico:

- Dia da Mulher: começou a ser explorado muito modestamente no inicio da década dos 90s. Em principio, apostava-se que seria o segundo Dia das Mães. Depois, passou-se a investir na data como um momento de as empresas homenagearem suas funcionárias. Hoje, tornou-se uma data institucional. O varejo compra botões de rosas para distribuir às suas clientes nessa data, fortalecendo relacionamentos e criando fidelidade. São clientes para essa data: postos de gasolina, restaurantes, hotéis e outros.

- Dia das Mães: uma das datas mais tradicionais do nosso mercado, sempre teve como objeto final a esposa, a mãe e a sogra. Com o aumento de opções de compras de presentes, as flores vieram perdendo espaço, passando a ser um produto secundário. Em geral, se o casal tem mais de um ano, o presente principal é outro. De outro lado, no nascimento do filho, 
a entrega de flores ainda é muito rara. Para o futuro, em vista das mudanças sociodemográficas por que passamos, deve-se fortalecer a entrega de flores para avós e sogras (o que significará também um crescimento em datas como o Dia da Avó).

Outro nicho que se tem firmado nessa data é a entrega de flores para "filhas". Nos casos de adolescentes que tiveram filhos e outras situações semelhantes, as flores aparecem como um presente importante, mesmo acompanhadas de outro tipo de presente, como forma de fortalecer o relacionamento.

Também deve fortalecer-se o mercado institucional. A venda de botões para empresas distribuírem a sua clientela feminina, como modo de homenagem (tal qual o Dia da Mulher), deve crescer. As flores estão-se firmando cada vez mais como ferramenta de marketing.

- Dia dos Namorados: essa data nasceu com o objetivo de presentear as companheiras que ainda não eram esposas. Hoje, também pela busca das pessoas em fortalecer seus relacionamentos e suas famílias, a data adquire novas características, ampliando-se para o Dia da esposa. Além disso, devido a anos de investimento em divulgação das flores (mesmo que involuntariamente), acabou por consolidar-se o seu consumo no segmento teen. Assim, a venda de flores para adolescentes tornou-se representativa. Também é nesse nicho que se verifica a maior venda das lojas da WEB.

- Dia da Secretária: queiramos assumir ou não, a primeira intenção do Dia da Secretária era presentear a amante. Isso não vingou. Hoje, a data atende realmente às funcionárias da empresa (mesmo aquelas que não exercem a função), possibilitando usar o produto como ferramenta de endomarketing, através dos departamentos de RH.

\section{A PRODUÇÃO DE FLORES E PLANTAS ORNAMENTAIS}

Os dados apresentados a seguir têm como fonte levantamentos e estimativas de técnicos ligados ao setor, assim como informações publicadas no estudo "Prospecção de Produtos e Mercados: Cadeia Produtiva Nacional", parceria do IBRAFLOR e APEX ${ }^{3}$, de 2003.
Em termos gerais, o estudo confirma a expansão da produção brasileira de flores e plantas ornamentais, ainda concentrada no Estado de São Paulo, destacando-se Rio de Janeiro, Minas Gerais, Santa Catarina, Paraná, Rio Grande do Sul, Pernambuco e Ceará, assim como outros estados da região Norte.

Em estimativa de AKI (1999) ${ }^{4}$, o número de produtores que desenvolviam atividades voltadas ao setor de flores e plantas ornamentais no Brasil era de 2.545. Em termos regionais, o Sudeste vinha em primeiro lugar, com $77 \%$ do total, seguido do Sul, com $19 \%$, Nordeste, com 3,1\%, e Noroeste e Centro-Oeste, com $0,8 \%$ cada um. São Paulo liderava com 59\%, seguido de Minas Gerais, com 14\%, e Rio Grande do Sul, com $11 \%$.

No estudo do IBRAFLOR (2003), foram cadastradas 1.356 propriedades onde a atividade é desenvolvida. Embora os números totais não sejam comparáveis (produtores X propriedades), torna-se interessante uma análise da participação percentual dos estados no total. São Paulo participa com $60 \%$, seguido do Paraná com 9\%, Santa Catarina com 8,4\% e Minas Gerais com 6,3\%. Esses estados representam mais de $80 \%$ do total brasileiro.

Dos 25 municípios com maior número de propriedades voltadas a essa atividade, 16 estão em São Paulo, 3 em Santa Catarina, 2 no Rio Grande do Sul e 1 em Minas Gerais, Rio de Janeiro, Pernambuco e Paraná. A concentração de propriedades dedicadas a essa atividade pode-se constituir em vantagem competitiva, dada a escala de produção, no relacionamento a montante e a jusante da cadeia.

A Tabela 1 apresenta a estimativa de área cultivada com diferentes tecnologias, por Estado. A área total cultivada é de 5.118 hectares, sendo $70,5 \%$ no campo, 26,3\% em estufa e 3,3\% em telado. O Estado de São Paulo detém 71,8\% da área nacional de cultivo, seguido por Santa Catarina com 11,6\% e Minas Gerais com $2,8 \%$. Os dados indicam uma área média nacional de 3,8 hectares/produtor, mostrando diferenças no uso de técnicas entre os estados. Tomando os três principais estados em área cultivada, enquanto São Paulo tem $69 \%$ da área cultivada no campo, Santa Catarina tem $96 \%$ e Minas Gerais apenas 26\%. Essas diferenças também se manifestam nos demais estados.

\footnotetext{
${ }^{3}$ IBRAFLOR/APEX. Prospecção de Produtos e Mercados: Cadeia Produtiva Nacional - Relatório do Diagnóstico da Produção de Flores e Plantas Ornamentais Brasileira, CD-Rom, Campinas, 2003.

${ }^{4}$ IBRAFLOR, 2003, tabela 1, p.7.
} 
Tabela 1. Área cultivada por técnica de produção (em hectare e porcentagem) por Estado

\begin{tabular}{lrcccc}
\hline Estado & Total geral & & Campo & Estufa & Telado \\
\hline & ha & $\%$ & $\%$ & $\%$ & $\%$ \\
Alagoas & 66,3 & 1,30 & 97,0 & 1,1 & 2,1 \\
Amazonas & 12,1 & 0,24 & 83,5 & 16,5 & - \\
Bahia & 41,8 & 0,82 & 89,0 & 1,4 & 9,3 \\
Ceará & 46,9 & 0,92 & 72,9 & 21,7 & 5,3 \\
Espírito Santo & 10,0 & 0,20 & 21,0 & 76,0 & 3,0 \\
Goiás & 31,6 & 0,62 & 93,0 & 2,5 & 4,4 \\
Minas Gerais & 141,7 & 2,77 & 26,2 & 68,8 & 5,0 \\
Pará & 44,5 & 0,87 & 100,0 & - & - \\
Paraíba & 3,0 & 0,06 & 100,0 & - & - \\
Pernambuco & 53,2 & 1,04 & 83,8 & 12,2 & 4,1 \\
Paraná & 138,0 & 2,70 & 76,4 & 22,9 & 0,7 \\
Rio de Janeiro & 136,0 & 2,66 & 66,3 & 33,6 & 67,0 \\
Rio Grande do Sul & 125,6 & 2,45 & 95,7 & 3,7 & 0,2 \\
Santa Catarina & 592,5 & 11,58 & 68,8 & 29,7 & 0,6 \\
São Paulo & $3.675,10$ & 71,81 & 70,5 & 26,3 & 3,4 \\
Total geral & $5.118,10$ & 100,00 & & 3,3 \\
\hline
\end{tabular}

Fonte: Elaborada pelos autores a partir de dados do IBRAFLOR, 2003.

A relação entre técnicas de cultivo e as principais categorias de flores e plantas ornamentais pode ser mais bem visualizada na Tabela 2 .

Cerca de $86 \%$ da categoria mudas de plantas ornamentais é cultivada no campo, e 53\% de flores em vaso, em estufa.

O uso de diferentes tecnologias está ligado ao grau de modernização dessa atividade nas diversas regiões, mas também às espécies mais cultivadas num e noutro caso.
O Rio de Janeiro, por exemplo, tem a maior proporção de cultivo sob telado, o que deve expressar a especialização da produção carioca em mudas de plantas ornamentais. Da mesma forma, Alagoas, Bahia e Pernambuco têm alta proporção do cultivo no campo, que deve estar relacionado com plantas tropicais de corte, e em Santa Catarina e Goiás, com a produção de mudas de plantas ornamentais, entre elas forrações e gramas.

Tabela 2. Técnicas de cultivo por categoria em porcentagem e hectare

\begin{tabular}{lrrrrr}
\hline Categoria & Campo & Estufa & Telado & Total & Total \\
\cline { 2 - 4 } & & ha & & $\%$ & ha \\
Flores de corte & 55,3 & 43,4 & 1,3 & 100,0 & $1.476,0$ \\
Folhagem de corte & 64,4 & 31,9 & 3,7 & 100,0 & 134,9 \\
Flores em vaso & 45,1 & 53,3 & 1,7 & 100,0 & 673,0 \\
Folhagem em vaso & 59,7 & 35,6 & 4,7 & 100,0 & 160,2 \\
Mudas de plantas ornamentais & 86,2 & 9,0 & 4,8 & 100,0 & $2.579,4$ \\
Outras & 85,6 & 13,5 & 0,8 & 100,0 & 94,70 \\
Total geral (\%) & 70,5 & 26,3 & 3,3 & 100,0 & $5.118,1$ \\
Total geral (ha) & $3.606,9$ & $1.343,9$ & 167,3 & - & $5.118,1$ \\
\hline
\end{tabular}

Fonte: Elaborada pelos autores a partir de dados do IBRAFLOR, 2003. 
A categoria de maior área cultivada é a de mudas de plantas ornamentais, com 2.579,4 hectares, destacando-se os arbustos e trepadeiras $(901,4$ hectares) com $90 \%$ do cultivo no campo.

$\mathrm{Na}$ categoria flores de corte, segundo em área cultivada (1.476 hectares), destacam-se os cultivos de rosas e crisântemos, responsáveis por cerca de $45 \%$ da área total cultivada nessa categoria.

A área cultivada com flores de vaso foi de 673 hectares, destacando-se os cultivos de crisântemos, orquídeas, azaléias e minirrosas que, juntos, são responsáveis por $35 \%$ da área total nessa categoria.

Folhagem em vaso ocupa uma área menor (160 hectares), sendo suas principais plantas samambaias, cicas e filodendros, responsáveis por $47 \%$ da área total.

Fator de competitividade importante nas diferentes regiões produtoras, a infra-estrutura disponível também guarda uma relação com o grau de modernização, tipo de planta cultivada e mercado de destino. No levantamento de campo da pesquisa citada relacionaram-se a capacidade de armazenamento em câmaras frias, galpões de serviços e outras instalações. A Tabela 3 mostra essa capacidade por Estado. São Paulo participa com $81 \%$ da capacidade em câmaras frias e com $69 \%$ das instalações de galpão de serviços.
Na Tabela 4, encontram-se o número de propriedades e a capacidade média em instalações e benfeitorias. As propriedades com câmara fria no Estado de São Paulo tinham uma capacidade média de $117 \mathrm{~m}^{3}$, a maior encontrada no País. Já nos galpões de serviços, a maior média foi no Rio de Janeiro (466 $\left.\mathrm{m}^{2}\right)$, seguido por Minas Gerais $\left(319 \mathrm{~m}^{2}\right)$.

O uso de tecnologia e de modernização está diretamente ligado ao nicho de mercado escolhido pelo produtor. Os produtores de flores em vaso são os maiores demandadores e investidores na modernização. Isso se tem refletido na estabilidade da produção, que tem oferta constante durante o ano todo e produção tecnicamente viável em qualquer parte do País (o que deve sempre ser acompanhado de uma analise econômica do investimento).

O segundo grupo, o mais ligado à tecnologia de produção, é de flores de corte. Em que pese que muitos itens sejam produzidos em áreas abertas, aqueles de maior valor agregado somente podem ser obtidos mediante ambientes controlados. Ainda assim, as grandes mudanças de clima do ano (maior luminosidade ou menor temperatura) afetam a produção, mesmo dentro de estufas. Para esses dois casos, o uso de mão-de-obra é seletivo e altamente especializado.

Tabela 3. Capacidade das benfeitorias e instalações por Estado

\begin{tabular}{|c|c|c|c|c|c|c|}
\hline \multirow[t]{2}{*}{ Estados } & \multicolumn{2}{|c|}{ Camara fria } & \multicolumn{2}{|c|}{ Galpão de serviço } & \multicolumn{2}{|c|}{ Outras instalações } \\
\hline & $\mathrm{m}^{3}$ & $\%$ & $\mathrm{~m}^{2}$ & $\%$ & $\mathrm{~m}^{2}$ & $\%$ \\
\hline Alagoas & 60 & 0,14 & 2.106 & 0,55 & - & - \\
\hline Amazonas & - & - & 1.945 & 0,51 & - & - \\
\hline Bahia & 117 & 0,27 & 1.760 & 0,46 & - & - \\
\hline Ceará & 293 & 0,69 & 2.865 & 0,75 & 150 & 0,34 \\
\hline Espírito Santo & 171 & 0,40 & 1.940 & 0,51 & - & - \\
\hline Goiás & - & - & 870 & 0,23 & 6.950 & 15,59 \\
\hline Minas Gerais & 2.753 & 6,45 & 33.861 & 8,85 & - & - \\
\hline Pará & 75 & 0,18 & 2.255 & 0,59 & - & - \\
\hline Pernambuco & 43 & 0,10 & 995 & 0,26 & 110 & 0,25 \\
\hline Paraná & 2.197 & 5,15 & 12.366 & 3,23 & - & - \\
\hline Rio de Janeiro & 60 & 0,14 & 24.234 & 6,33 & 430 & 0,96 \\
\hline Rio Grande do Sul & 2.112 & 4,95 & 11.335 & 2,96 & - & - \\
\hline Santa Catarina & 380 & 0,89 & 22.001 & 5,75 & 24.243 & 54,40 \\
\hline São Paulo & 34.393 & 80,63 & 264.106 & 69,02 & 12.685 & 28,46 \\
\hline Total & 42.654 & 100,00 & 382.639 & 100,00 & 44.568 & 100,00 \\
\hline
\end{tabular}

Fonte: Elaborada pelos autores a partir de dados do Ibraflor 2003. 
Tabela 4. Número de propriedades e capacidade média/propriedade, por Estado

\begin{tabular}{lrcrccc}
\hline Estados & \multicolumn{2}{c}{ Camara fria } & \multicolumn{2}{c}{ Galpão de serviço } & \multicolumn{2}{c}{ Outras instalacões } \\
\hline & $\mathrm{N} .{ }^{\circ}$ & Capac. média & $\mathrm{N} .{ }^{\circ}$ & Capac. média & N. ${ }^{\circ}$ & Capac. média \\
Alagoas & 1 & & & & & - \\
Amazonas & - & 60,0 & 31 & 67,9 & - & - \\
Bahia & 5 & - & 11 & 176,8 & - & - \\
Ceará & 4 & 73,4 & 17 & 103,5 & - & 37,5 \\
Espírito Santo & 6 & 28,5 & 19 & 150,8 & 4 & - \\
Goiás & - & - & 7 & 149,2 & - & 1737,5 \\
Minas Gerais & 39 & 70,6 & 106 & 319,4 & - & - \\
Pará & 1 & 75,0 & 11 & 205,0 & - & - \\
Pernambuco & 3 & 14,3 & 25 & 39,8 & 2 & 55,0 \\
Paraná & 46 & 47,8 & 82 & 150,8 & - & - \\
Rio de Janeiro & 2 & 30,0 & 52 & 466,0 & 3 & 143,3 \\
Rio Grande do Sul & 37 & 57,1 & 91 & 124,6 & - & - \\
Santa Catarina & 4 & 95,0 & 133 & 165,4 & 111 & 218,4 \\
São Paulo & 293 & 117,4 & 858 & 307,8 & 23 & 551,5 \\
Total & 441 & 96,7 & 1.456 & 262,8 & 147 & 303,2 \\
\hline
\end{tabular}

Fonte: Elaborada pelos autores a partir de dados do Ibraflor 2003.

As espécies cultivadas e o grau de modernização têm relação à intensidade no uso de mão-de-obra. A Tabela 5 mostra o emprego gerado nos diferentes estados. Nas propriedades onde a produção é voltada para o paisagismo e para as plantas ornamentais, o uso de mão-de-obra é mais intensivo. Do total de empregos gerados, cerca de $94 \%$ são de mão-de-obra permanente e $6 \%$ de temporário.

Tabela 5. Emprego gerado no setor, por Estado

\begin{tabular}{|c|c|c|c|c|c|}
\hline Estado & Propriedades & $\begin{array}{c}\text { Área } \\
\text { cultivada }\end{array}$ & $\begin{array}{c}\text { Empregos } \\
\text { gerados }\end{array}$ & $\begin{array}{c}\text { Empregos por } \\
\text { propriedade }\end{array}$ & $\begin{array}{c}\text { Empregos } \\
\text { por ha }\end{array}$ \\
\hline & N. ${ }^{o}$ & ha & 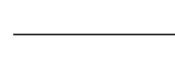 & N..$^{o}$ & 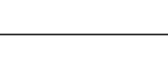 \\
\hline Alagoas & 33 & 66,3 & 230 & 7,0 & 3,5 \\
\hline Amazonas & 8 & 12,1 & 49 & 6,1 & 4,0 \\
\hline Bahia & 19 & 41,8 & 150 & 7,9 & 3,6 \\
\hline Ceará & 24 & 46,9 & 545 & 22,7 & 11,6 \\
\hline Espírito Santo & 13 & 10,0 & 81 & 6,2 & 8,1 \\
\hline Goiás & 5 & 31,6 & 91 & 18,2 & 2,9 \\
\hline Minas Gerais & 86 & 141,7 & 1.181 & 13,7 & 8,3 \\
\hline Pará & 11 & 44,5 & 159 & 14,5 & 3,6 \\
\hline Paraíba & 1 & 3,0 & 4 & 4,0 & 1,3 \\
\hline Pernambuco & 25 & 53,2 & 219 & 8,8 & 4,1 \\
\hline Paraná & 121 & 138,0 & 719 & 5,9 & 5,2 \\
\hline Rio de Janeiro & 25 & 136,0 & 282 & 11,3 & 2,1 \\
\hline Rio Grande do Sul & 52 & 125,6 & 820 & 15,8 & 6,5 \\
\hline Santa Catarina & 114 & 592,5 & 815 & 7,1 & 1,4 \\
\hline São Paulo & 819 & $3.675,1$ & 13.847 & 16,9 & 3,8 \\
\hline Total & 1.356 & $5.118,1$ & 19.192 & 14,2 & 3,7 \\
\hline
\end{tabular}

Fonte: IBRAFLOR 2003. 
A Tabela 6 mostra essa relação por Estado. No Amazonas e na Paraíba, as propriedades analisadas só utilizam mão-de-obra permanente e, mesmo assim, a maior parte é composta de funcionários, indicando uma atividade geradora de empregos não só para membros da família.

O Estado de São Paulo é responsável pela geração de 13.847 empregos nessa atividade, sendo, desse total, 97\% de empregos permanentes, $85 \%$ constituídos de mão-de-obra contratada e 15\%, familiar.

Entre as características das propriedades pesquisadas são apresentadas informações sobre gestão de interesse na capacitação dos produtores para participar do mercado. A Tabela 7 mostra o percentual de produtores que fazem escrituração, participam de treinamento e se utilizam de crédito.

Quase a metade das propriedades pesquisadas, $44 \%$, não faz escrituração e $57 \%$ não participam de treinamento. No total, apenas $31 \%$ já utilizaram crédito. Esses dados agregados apontam para uma necessidade de capacitação e mecanismos de inclusão dos produtores junto a fontes de financiamento, sendo importantes para enfrentar a concorrência que cresce no setor.

As diferenças entre os estados servem de indicador de vantagens competitivas no quesito gerenciamento.
Assim, o índice mais elevado de proprietários que fazem escrituração em Pernambuco, Paraná e São Paulo, indicaria maior capacidade de enfrentar mudanças e conquistar novos mercados. Da mesma forma, quanto ao crédito, importante na aquisição de tecnologias mais produtivas. $\mathrm{O}$ baixo índice de participação em treinamento em alguns estados também é preocupante, diante das transformações que se observam na demanda e nos sinais emitidos pelo consumidor.

Por último, são mostradas informações sobre a capacitação técnica dos produtores, tipificando a assistência recebida. Pela Tabela 8 , observa-se que cerca de $44 \%$ dos produtores não se utilizam de assistência técnica, pública ou privada. Daqueles que a utilizam, a grande maioria o faz com assistência técnica privada, indicando uma ausência do setor público na esfera da produção. Como exceções a essa realidade, encontram-se Ceara, Paraná, Pará e Rio Grande do Sul, onde a assistência técnica oficial é adotada por um número maior de produtores.

As informações contidas nas Tabelas 7 e 8 são importantes para compor um quadro da situação dos produtores nas diversas regiões, ante as demandas futuras de um mercado cuja concorrência se torna cada vez mais acirrada.

Tabela 6. Tipo de mão-de-obra utilizada

\begin{tabular}{lccrrrrrr}
\hline \multirow{2}{*}{ Estado } & \multicolumn{3}{c}{ Permanente } & & \multicolumn{3}{c}{ Temporária } & Total \\
\cline { 2 - 3 } & Família & Funcionários & Total & & Família & Funcionários & Total & \\
\hline Alagoas & 1,84 & 0,78 & 76,96 & & 0,00 & 5,44 & 23,04 & 1,20 \\
Amazonas & 0,39 & 0,24 & 100,00 & & 0,00 & 0,00 & 0,00 & 0,26 \\
Bahia & 0,97 & 0,56 & 76,67 & & 0,00 & 3,59 & 23,33 & 0,78 \\
Ceará & 0,73 & 3,06 & 87,52 & & 0,00 & 6,98 & 12,48 & 2,84 \\
Espírito Santo & 0,73 & 0,32 & 88,89 & & 4,49 & 0,51 & 11,11 & 0,42 \\
Goiás & 0,30 & 0,45 & 84,62 & & 4,49 & 1,03 & 15,38 & 0,47 \\
Minas Gerais & 5,59 & 6,15 & 92,89 & & 16,85 & 7,08 & 7,11 & 6,15 \\
Pará & 2,63 & 0,42 & 93,71 & & 0,00 & 1,03 & 6,29 & 0,83 \\
Paraíba & 0,03 & 0,02 & 100,00 & & 0,00 & 0,00 & 0,00 & 0,02 \\
Pernambuco & 0,91 & 1,16 & 92,24 & & 0,00 & 1,75 & 7,76 & 1,14 \\
Paranán & 7,11 & 2,58 & 85,81 & & 3,37 & 10,16 & 14,19 & 3,75 \\
Rio de Janeiro & 0,97 & 1,52 & 91,13 & & 0,00 & 2,57 & 8,87 & 1,47 \\
Rio Grande do Sul & 7,38 & 2,71 & 78,78 & & 53,93 & 12,94 & 21,22 & 4,27 \\
Santa Catarina & 8,62 & 3,02 & 89,82 & & 2,25 & 8,32 & 10,18 & 4,25 \\
São Paulo & 61,81 & 77,01 & 97,19 & & 14,61 & 38,60 & 2,81 & 72,15 \\
Total geral & 100,00 & 100,00 & 94,46 & 100,00 & 100,00 & 5,54 & 100,00 \\
\hline
\end{tabular}

Fonte: Elaborada pelos autores a partir de dados do IBRAFLOR 2003. 
Tabela 7. Perfil gerencial dos produtores, por Estado

\begin{tabular}{|c|c|c|c|c|c|c|c|}
\hline \multirow[t]{2}{*}{ Estado } & \multicolumn{2}{|c|}{$\begin{array}{l}\text { Realizam } \\
\text { escrituracão }\end{array}$} & \multicolumn{2}{|c|}{$\begin{array}{c}\text { Participam } \\
\text { de treinamento }\end{array}$} & \multicolumn{2}{|c|}{ Utilizam crédito } & \multirow[t]{2}{*}{ Total } \\
\hline & Qtde. & $\%$ & Qtde. & $\%$ & Qtde. & $\%$ & \\
\hline Alagoas & 33 & 100,0 & 32 & 97,0 & 13 & 39,4 & 33 \\
\hline Amazonas & - & 0,0 & 5 & 62,5 & - & 0,0 & 8 \\
\hline Bahia & 11 & 57,9 & 16 & 84,2 & 5 & 26,3 & 19 \\
\hline Ceará & 9 & 37,5 & 10 & 41,7 & 5 & 20,8 & 24 \\
\hline Espírito Santo & 6 & 46,2 & 8 & 61,5 & 3 & 23,1 & 13 \\
\hline Goiás & 1 & 20,0 & 3 & 60,0 & - & 0,0 & 5 \\
\hline Minas Gerais & 12 & 14,0 & 12 & 14,0 & 4 & 4,7 & 86 \\
\hline Pará & 4 & 36,4 & 10 & 90,9 & 1 & 9,1 & 11 \\
\hline Paraíba & - & 0,0 & 1 & 100,0 & - & 0,0 & 1 \\
\hline Pernambuco & 17 & 68,0 & 20 & 80,0 & 13 & 52,0 & 25 \\
\hline Paraná & 79 & 64,8 & 111 & 91,0 & 30 & 24,6 & 122 \\
\hline Rio de Janeiro & 1 & 4,0 & 23 & 92,0 & 2 & 8,0 & 25 \\
\hline Rio Grande do Sul & 27 & 51,9 & 36 & 69,2 & 30 & 57,7 & 52 \\
\hline Santa Catarina & 23 & 20,2 & 62 & 54,4 & 33 & 28,9 & 114 \\
\hline São Paulo & 537 & 65,6 & 235 & 28,7 & 286 & 35,0 & 818 \\
\hline Total geral & 760 & 56,0 & 584 & 43,1 & 425 & 31,3 & 1.356 \\
\hline
\end{tabular}

Fonte: IBRAFLOR 2003.

Tabela 8. Tipificação da assistência técnica, por Estado

\begin{tabular}{|c|c|c|c|c|c|}
\hline Estado & Não utiliza & Of./Pr. & Oficial & Privada & Total geral \\
\hline Alagoas & 3,03 & 0,00 & 0,00 & 96,97 & 100,00 \\
\hline Amazonas & 62,50 & 0,00 & 0,00 & 37,50 & 100,00 \\
\hline Bahia & 52,63 & 0,00 & 10,53 & 36,84 & 100,00 \\
\hline Ceará & 29,17 & 0,00 & 54,17 & 16,67 & 100,00 \\
\hline Espírito Santo & 46,15 & 0,00 & 7,69 & 46,15 & 100,00 \\
\hline Goiás & 20,00 & 0,00 & 0,00 & 80,00 & 100,00 \\
\hline Minas Gerais & 8,14 & 0,00 & 0,00 & 91,86 & 100,00 \\
\hline Pará & 18,18 & 0,00 & 27,27 & 54,55 & 100,00 \\
\hline Paraíba & 0,00 & 0,00 & 0,00 & 100,00 & 100,00 \\
\hline Pernambuco & 16,00 & 0,00 & 0,00 & 84,00 & 100,00 \\
\hline Paraná & 43,44 & 0,00 & 31,97 & 24,59 & 100,00 \\
\hline Rio de Janeiro & 8,00 & 0,00 & 0,00 & 92,00 & 100,00 \\
\hline Rio Grande do Sul & 34,62 & 0,00 & 25,00 & 40,38 & 100,00 \\
\hline Santa Catarina & 32,46 & 0,00 & 11,40 & 56,14 & 100,00 \\
\hline São Paulo & 53,30 & 0,12 & 4,89 & 41,69 & 100,00 \\
\hline Total geral & 43,44 & 0,07 & 9,14 & 47,35 & 100,00 \\
\hline
\end{tabular}

Fonte: Elaborada pelos autores a partir de dados do IBRAFLOR 2003. 


\section{CONSIDERAÇÕES FINAIS}

Dadas as informações sobre consumo e estruturação da produção, algumas considerações são importantes.

O mercado de flores e plantas ornamentais está distribuído por todo o País, tanto no consumo quanto na produção. O número de novos empreendedores que ingressam no setor produtivo a cada ano é surpreendente, em grande parte devido à atenção despertada pela mídia.

Esses novos produtores vêm, basicamente, de três origens a saber:

- Investidores que enxergam oportunidades de exportação no produto (principalmente no Nordeste);

- Pequenos produtores que estão mudando de outros produtos agrícolas que exigem grande escala de produção (principalmente no Sul do País).

- Proprietários rurais que estão investigando uma nova atividade agrícola.

O crescimento da Hortitec - maior evento de tecnologia de produção para flores do País - é excelente termômetro para dimensionar esse interesse.

Um pouco atrás dessa demanda, chegam o apoio técnico e o financeiro. Para técnicos que trabalham nessa área, observa-se na esfera da produção que, em grande parte, o próprio produtor tem que aprender com seus erros, ou o que pode ser pior, começa com o produto mais fácil (e de menor erro na produção), mas onde encontrará o maior numero de concorrentes.

Outro problema observado é o desafio da comercialização. O varejo tradicional vê com desconfiança esse novo produtor, que, muitas vezes, não oferece uma padronização adequada nem volumes freqüentes.

Diante do exposto, são listadas as seguintes medidas essenciais para quebrar esse circulo:
- A capacitação empresarial dos futuros novos produtores é uma ferramenta fundamental para organizar o futuro desse mercado. Poderia ser amarrada à exigência de um Plano de Negócios para obtenção de apoio técnico.

- A capacitação técnica dos produtores existentes é uma cruzada que precisa ser feita já, pois é esse desnivelamento que se acaba mostrando o maior obstáculo para o associativismo.

- Fomentar o agrupamento dos produtores em pequenas instituições, onde o poder do grupo e a mobilidade administrativa possam realmente criar sinergia.

- Direcionar os grupos de produtores para soluções comuns de comercialização. Somente assim podem-se criar regras claras de vendas, o que não elimina as dores de mercado (oferta $\mathrm{x}$ demanda), mas garante que cada produtor terá uma chance de sucesso bem maior do que a que encontra com a desestruturação atual.

Finalmente, mas não menos importante, é preciso olhar para o varejo. O produto somente está vendido depois que o consumidor final fica satisfeito. Se o varejista não estiver também capacitado, orientado e parceirizado com o produtor, muita energia será desperdiçada em vão dentro da cadeia produtiva.

Em nenhum mercado existe uma união total entre todos os produtores e todos os varejistas, e isso não precisa assim ser um objetivo, mas nenhum mercado consegue firmar-se se não houver pequenas cadeias estabelecidas entre produtores e varejo final. O produtor precisa resistir à tentação de verticalizarse e concentrar sua solução comercial na seleção/ investimento em clientes, mas isso só é possível com o associativismo - e aí retorna-se ao início, pois não há associativismo sem homogeneidade técnico-financeira e liderança.

O mercado existe, as oportunidades também. Esses gargalos são somente o pretexto para encarar tais desafios. 